Resenhas 


\section{O programa científico do Antropoceno}

\section{Ricardo Soares ${ }^{I}$ e Wilson Machado ${ }^{I I}$}

V ano 2000, o Prêmio Nobel de 1 Química Paul Crutzen e o liminologista Eugene Stoermer publicaram na Newsletter do International Geosphere-Biosphere Programme (IGBP) a hipótese na qual a atual Época geológica do planeta Terra, o Holoceno, havia se encerrado e em seu lugar se iniciara o que viria a ser reconhecido como o "Antropoceno" (Crutzen; Stoermer, 2000). Dessa forma, conceituaram a nova unidade cronoestatigráfica como resultado direto das mudanças ambientais globais proporcionadas pelas ações da humanidade a partir da Revolução Industrial, iniciada no século XVIII com o advento da máquina a vapor de James Watt. Logo, teve início a formalização que a humanidade teria se convertido em uma força geológica poderosa e capaz de alterar irreversivelmente o futuro do planeta.

Mesmo que o Antropoceno apresente certo caráter polêmico e não seja ainda um consenso absoluto nas geociências, nem tampouco nas ciências humanas, devido a grande repercussão na comunidade científica internacional e a um aumento exponencial do interesse na discussão sobre a validade ontológica e epistemológica (Crutzen, 2002), a Subcomissão de Estratigrafia do Quaternário (órgão da União Internacional de Ciências Geológicas - IUGS) considerou que o conceito possuía "mérito estratigráfico" o suficiente para a sua formalização e criou, em 2009, o Grupo de Trabalho do Antropoceno (GTA), cuja finalidade é avaliar se o atual cenário de exploração científica poderia se consti- tuir no reconhecimento de um novo paradigma, e se esta Época poderia formalmente fazer parte da Escala de Tempo Geológica internacional (Silva; Arbilla, 2018; Silva et al., 2020).

Como pode ser observada na Figura 1, após a obtenção de um consenso de, no mínimo, $60 \%$ dos membros do GTA a proposta do Antropoceno deverá ser posta à aprovação da Subcomissão de Estratigrafia do Quaternário. Caso aceite os argumentos científicos apresentados, essa subcomissão fará a recomendação à Comissão de Estratigrafia para que, caso também aprove o conjunto de evidências e argumentos científicos apresentados nas etapas anteriores, consolide a proposta para a aprovação pelo Comitê Executivo da IUGS. Esse Comitê será o responsável por atualizar a Escala Geológica de Tempo, constando o Antropoceno como a Época mais recente na história da Terra. Era previsto, inicialmente, que a Subcomissão de Estratigrafia do Quaternário apresentaria a sua decisão durante ao $36^{\text {a }}$ Congresso Geológico Mundial que seria realizado em março de 2020. Infelizmente, em razão da pandemia do Covid-19, esse congresso teve que ser adiado para novembro de 2020 , fazendo que todo o processo de ratificação do reconhecimento formal do Antropoceno como Época geológica continue em andamento (Figura 1).

O conjunto de dados obtidos e hipóteses levantadas ao longo de uma década pelo GTA têm sido apresentado de maneira crítica e coerente em uma grande variedade de livros e artigos científicos internacionais, assim como foram expos- 
tos no $35^{\circ}$ Congresso Geológico Internacional, em 2016 (Silva et al., 2018), sendo posteriormente compilados e sumarizados no livro The Anthropocene as a Geological Time Unit: A Guide to the Scientific Evidence and Current Debate, editdo pelos pesquisadores Jan Zalsiewicz, Colin Waters, Mark Williams e Colin Summerhayes (Alasiewicz et al., 2019).

O livro se divide em sete capítulos e conta com a contribuição de 38 dos mais renomados cientistas internacionais atuantes na teoria do Antropoceno. Contudo, embora se observe um grande esforço em proporcionar uma leitura acessível, pelo caráter multidisciplinar e bastante específico do tema, pode se constituir num grande desafio a leitores não familiarizados com a linguagem científica em geral, e com conceitos geológicos em particular.

O primeiro capítulo, "História e desenvolvimento do Antropoceno como um conceito estratigráfico", expõe como a hipótese do Antropoceno despertou profundo interesse da comunidade científica internacional, principalmente quando foi mais bem elaborada e divulgada na renomada revista Nature (Crutzen, 2002).

Os autores destacam que as ciências naturais foram aquelas que, informalmente, mais utilizaram o Antropoceno para abordar diferentes assuntos inerentes ao Sistema Terra tais como, mudanças climáticas globais, extinção das espécies, acidificação dos oceanos, alteração dos ciclos biogeoquímicos, acumulação de tecnofósseis entre outros (Silva; Arbilla, 2018). Além disso, enfatiza-se constantemente que o objetivo do livro é descrever o Antropoceno somente de um ponto de vista geológico, mas sem adotar um caráter excludente ou polari- zante entre diferentes ramos da Ciência, como pode ser observado em "[...] esta definição não exclui outras diferentes interpretações do Antropoceno que apareceram nos anos recentes entre outras comunidades acadêmicas, particularmente nas ciências humanas" (p.l), mas sem tergiversar em seu rígido caráter científico "[Antropoceno] não tem significância particular ou caráter simbólico [...] é um fenômeno geológico de um planeta profundamente impactado pelos seres humanos" (p.15).

No segundo capítulo, "Assinaturas estratigráficas do Antropoceno", são apresentadas as evidências científicas que baseiam o Antropoceno, com especial ênfase no uso dos distintos marcadores estratigráficos estocados em diferentes compartimentos ambientais, que são elegíveis a serem reconhecidos como o registro geológico definitivo (golden spike) do início da ação antropogênica sincrônica e global do Antropoceno. As Terras Pretas de Índio (TPI) da Região Amazônica são destacadas como possíveis golden spikes, mesmo apresentando características pedológicas que as definam apenas como interessante marcador da presença antrópica da Bacía Amazônica (Soares et al., 2018).

O terceiro capítulo, intitulado "A assinatura bioestratigráfica do Antropoceno", apresenta como os fósseis podem fornecer informações fundamentais nas alterações das composições das espécies durante as mudanças sofridas no Sistema Terra ao longo das Eras geológicas. As evidências apontam que a humanidade poderá, e com razão, ser responsabilizada pela atual sexta extinção em massa de diferentes espécies ao redor do globo.

Ao longo do quarto capítulo, "A tecnosfera e seu registro estratigráfico", 


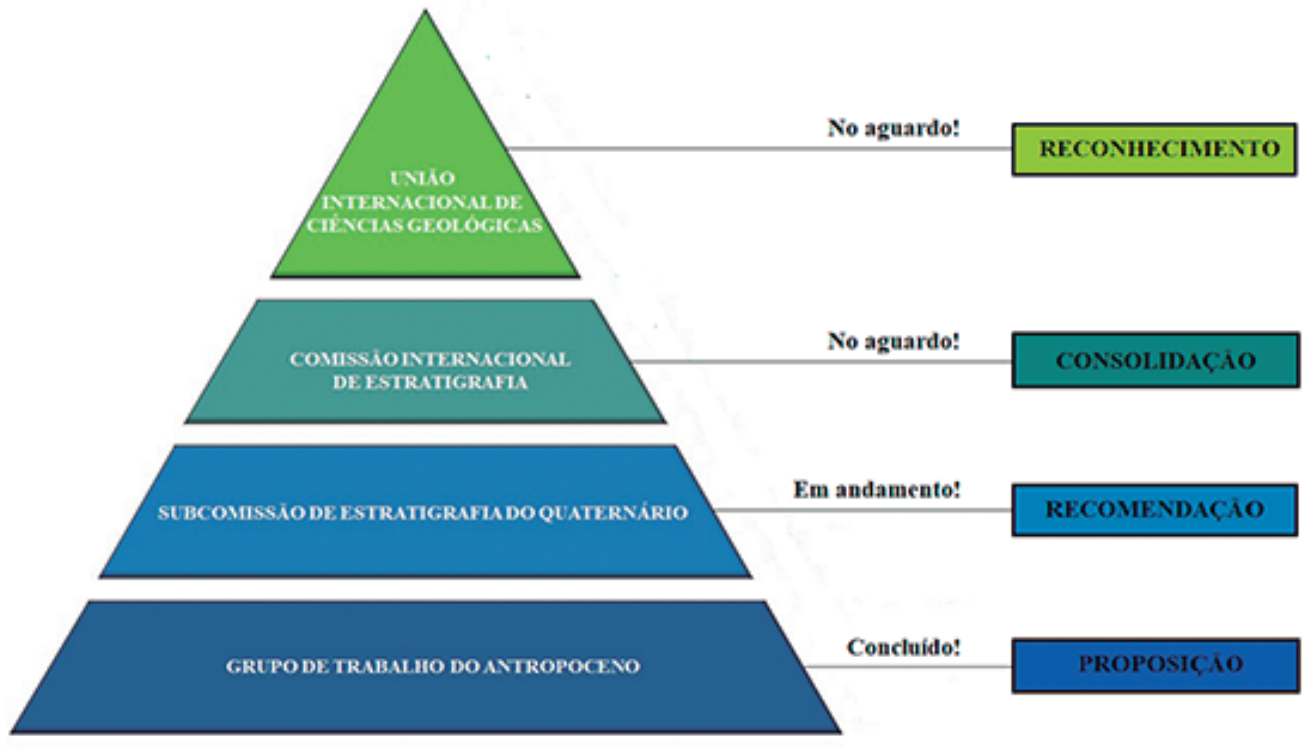

Fonte: Modificado de Silva et al. (2020).

Figura 1 - Processo de avaliação formal para o reconhecimento oficial da proposta do Antropoceno como Época geológica.

os autores apresentam a relação desse novo nicho de construção humana com o Antropoceno, com especial ênfase nos artefatos que podem servir de registros geocronológicos das atividades antrópicas no Sistema Terra. Contudo, ao considerarem os diferentes candidatos à tecnofósseis, os autores se limitaram, injustificadamente, a descrever quase que exclusivamente os plásticos, pois "[Plásticos] providenciam um registro físico distintivo da evolução da tecnosfera durante o século XX e início do século XXI" (p.155). Embora o plástico possua uma indiscutível importância e seja emblemático como potencial tecnofóssil, não se deveria omitir ou diminuir a importância do concreto, do alumínio elementar ou dos materiais eletroeletrônicos que apresentam a mesma tendência de produção massiva a partir da década de 1950, em um período histórico, informalmente, reconhecido como "A Grande Aceleração" (Silva et al., 2020).

O quinto capítulo, "Quimioestratigrafia do Antropoceno", elucida como a combinação da geoquímica com a estratigrafia pode ser usada para avaliar a variação das substâncias químicas através dos tempos, assim como “[...] definir padrões de alteração da composição química ao longo do tempo que podem fornecer marcadores para o Antropoceno como nova Época geológica” (p.158). Todavia, ao contrário do capítulo anterior, os autores se preocuparam em expor adequadamente os diferentes possíveis marcadores do início do Antropoceno e a tendência sugerida, timidamente, é que seja escolhido futuramente o fallout 
dos radionuclídeos gerados pelas detonações atmosféricas das armas nucleares, no período da guerra fria, como o marcador mais preciso dessa nova Época geológica.

Embora tenha sido propositalmente omitido pelos autores, caso realmente os radionuclídeos espalhados ao redor do planeta pelas explosões nucleares atmosféricas sejam futuramente escolhidos como definitivos Golden Spikes, isso poderá acarretar em severas e significativas implicações aos estudos das ciências humanas e sociais sobre o tema, que teriam que passar a considerar, também, a contribuição do Socialismo (socialismo real, socialismo com características chinesas etc.), além do sistema capitalista para o surgimento da Época do Antropoceno no Sistema Terra ao longo do século XX.

De forma correta, é constantemente enfatizado na obra que o Antropoceno não deve ser simplesmente confundido ou ter seu estatuto científico reduzido ao mero aumento das concentrações dos gases de efeito estufa (GEE), de origem antrópica, e que estão remodelando e afetando o atual estado de equilíbrio termodinâmico do planeta. Contudo, no sexto capítulo, "Mudanças climáticas e o Antropoceno", os autores elucidam a questão das mudanças climáticas globais com um enfoque paleoclimático, descrevendo o estado da arte dos mecanismos e processos biogeoquímicos naturais, desde o início da formação da atmosfera primitiva do planeta até a projeção de cenários futuros com seus respectivos impactos ambientais negativos ao equilíbrio térmico do Sistema Terra (derretimento de geleiras, aumento do nível do mar, acidificação dos oceanos etc.). Surpreendentemente, os autores, ao abordarem esse capítulo, não leva- ram em consideração que as mudanças climáticas globais constituem um dos principais Limites Planetários (espaço operacional seguro) para o desenvolvimento da Humanidade com respeito ao funcionamento do Sistema Terra (Silva; Arbilla, 2018).

Finalmente, o capítulo "O limite estratigráfico do Antropoceno" serve de epílogo, sumariza e critica as diversas propostas de origem sugeridas pela comunidade científica internacional: "PaleoAntropoceno", “Antropoceno precoce", hipótese "Orbis Spike", "Revolução Industrial", "Grande Aceleração" entre outras. Além disso, os autores reforçam que, independentemente da hipótese a ser reconhecida, o GTA trabalha somente com o “[...] 'Antropoceno geológico' essencialmente como originalmente pretendido, e não a outras interpretações" (p.286).

Em 2019, foi divulgado que 88\% dos membros do GTA ratificou a proposta que o Antropoceno fosse formalmente reconhecido como uma nova unidade cronoestatigráfica com início a partir da década de 1950, cabendo à Subcomissão de Estratigrafia do Quaternário decidir se apresentaria essa proposta à União Internacional de Ciências Geológicas no $36^{\circ}$ Congresso Geológico Internacional, a ser realizado em 2020, na cidade de Nova Délhi - Índia (Silva et al., 2020), como dito anteriormente. Contudo, devido à grave pandemia de Covid-19, até fevereiro de 2020 nem a Comissão de Estratigrafia, nem o Comitê Executivo da IUGS iniciaram as suas respectivas etapas de análise para a oficialização do Antropoceno como Época geológica. Logo, esse livro que representa o esforço de mais de dez anos de coleta de dados e evidências científicas deveria possuir 
um caráter mais conclusivo de como e quando se iniciou o Antropoceno, e não ser uma mera tentativa de resposta àqueles que criticam, acertadamente, que o GTA não dispunha de um corpus teórico robusto e baseado suficientemente no peso das evidências de forma que atenda ao rigor do método científico.

O livro The Anthropocene as a Geological Time Unit: A Guide to the Scientific Evidence and Current Debate representa uma contribuição imprescindível para a compreensão científica da evolução epistemológica sistemática da teoria relativa ao Antropoceno e, como dito antes, embora possa se constituir como desafiador ao público leigo torna-se primordial àqueles que queiram estar familiarizados com os debates mais recentes a respeito da "Época da Humanidade".

\section{Referências}

CRUTZEN, P. J. Geology of mankind. Nature, v.415, n.3, p.23, 2002.

CRUTZEN, P. J.; STOERMER, E. F. The Anthropocene. IGBP Global Change Newsletter, n.41, p.17-18, 2000.

SILVA, C. M.; ARBILLA, G. Antropoceno: os desafios de um novo mundo. Revista Virtual de Quimica, v.10, n.6, p.161947, 2018.

SILVA, C. et al. A nova Idade Meghalayan: o que isso significa para a Época do Antropoceno? Revista Virtual de Quimica, v.10, n.6, p.1648-58, 2018.

SILVA, C. M. et al.. Radionuclídeos como marcadores de um novo tempo: o Antropoceno. Quimica Nova, v.43, n.4, p.50614, 2020.

SOARES, R. et al. O Papel das Terras Pretas de Índio no Antropoceno. Revista Virtual de Química, v.10, n.6, p.1659-92, 2018.
ZALASIEWICZ, J. et al. (Ed.) The $A n$ thropocene as a Geological Time Unit: A Guide to the Scientific Evidence and Current Debate. Cambridge: Cambridge University Press. 2019. 361p.

Ricardo Soares é professor do Programa de Pós-Graduação em Geoquímica, Ins- tituto de Química, Universidade Fede- ral Fluminense, e do Instituto Estadual do Ambiente, Rio de Janeiro.

@ - ricardosoaresuff@gmail.com / http://orcid.org/0000-0002-0353-3174.

Wilson Machado é professor do Programa de Pós-Graduação em Geoquímica, Instituto de Química, Universidade Federal Fluminense. @ -wmachado@geoq.uff.br https://orcid.org/0000-0003-3117-8584.

Recebido em 4.4.2020 e aceito em 9.4.2020.

I, II Universidade Federal Fluminense, Instituto de Química, Niterói, Rio de Janeiro, Brasil. 